\title{
O DIREITO AGRÁRIO NO DEBATE SOBRE GÊNERO NO CAMPO: POSSIBILIDADES E DESAFIOS
}

\section{EL DERECHO AGRARIO EN EL DEBATE SOBRE EL GÉNERO EN EL CAMPO: OPORTUNIDADES Y DESAFÍOS}

\author{
${ }^{1}$ Rabah Belaidi \\ ${ }^{2}$ Larissa Carvalho de Oliveira
}

\section{RESUMO}

A questão de gênero no campo ainda se apresenta como um tema não encarado com a profundidade necessária pelo direito posto pelo Estado, em nosso país. A investigação principal deste trabalho consagra a realidade da mulher rural brasileira, de classe social baixa, no sentido de questionar o contexto em que o direito agrário contribui para a redução ou perpetua a desigualdade de gênero no campo. Trata-se de uma análise jurídica sobre determinado enfoque da realidade das camponesas, especialmente em tom crítico frente às suas dificuldades de acesso aos recursos agrícolas, à extensão rural, aos créditos, à terra e à permanência nela, entre outras circunstâncias que permanecem oferecendo barreiras às atividades autônomas das mulheres rurais. Objetiva-se verificar qual o papel do direito agrário no que tange às mulheres rurais e sinalizar, por meio da crítica à cientificidade moderna e opressora, debates necessários sobre o protagonismo local e a invisibilidade socioeconômica das camponesas, a partir de possíveis enfoques ecofeministas. Desta maneira, o presente estudo se estabelece com pesquisa bibliográfica, de acordo com o método dedutivo de análise. Em um primeiro momento, criticam-se as opressões patrocinadas pelo modelo agrícola hegemônico, no sentido de se incentivar práticas de resistência, especialmente ecofeministas. A pseudo-isenção do direito agrário quanto à questão de gênero no campo, mascara um posicionamento a favor do capital. Na sequência, há contextualização do debate, para tornar expresso o vínculo entre o ambiente rural, o agronegócio, as dificuldades de sobrevivência enfrentadas por camponesas e o direito agrário, relacionandose a preocupação com o meio ambiente ao feminismo e a necessidade de cobranças ao direito estatal, para que deixe de perpetuar a desigualdade de gênero e abra espaços de participação efetiva de mulheres rurais, nos momentos de tomadas de decisões. Finalmente, são apontadas noções para situar o entendimento sobre campesinato e, portanto, sobre camponesas.

Palavras-chave: Direito agrário, Camponesas, Gênero, Agronegócio

\footnotetext{
${ }^{1}$ Doutor em Direito pelo Université Panthéon-Assas, Paris (França). Professor Titular da Universidade Federal de Goiás - UFG, Goiás (Brasil). E-mail: rbelaidi@gmail.com

${ }^{2}$ Mestranda no Programa de Pós-Graduação em Direito Agrário da Universidade Federal de Goiás - UFG, Goiás (Brasil). E-mail: larissa.lco@gmail.com
} 


\section{RESUMEN}

La cuestión de género en el campo se presenta como un tema que no se ve con la profundidad requerida por el derecho puesto por el Estado en nuestro país. La investigación de este trabajo establece la realidad de las mujeres rurales brasileñas, de clase social baja, a cuestionar el contexto en el que el derecho agrario ayuda a reducir o perpetúa la desigualdad de género en el campo. Se trata de un análisis jurídico en un enfoque particular de la realidad de las mujeres rurales, sobre todo en tono crítico frente a sus dificultades en el acceso a los recursos agrícolas, extensión rural, a los créditos, a la tierra y permanecer en ella, entre otras condiciones que ofrecen las barreras a las actividades autónomas de las mujeres rurales. El objetivo es verificar el papel del derecho agrario en relación con las mujeres rurales e indicar, por medio de la crítica de la ciencia moderna y opresiva, debates necesarios sobre el destaque local y la invisibilidad socio-económica de las mujeres rurales, a partir de posibles enfoques ecofeministas. Por lo tanto, este estudio se estableció con la literatura, de acuerdo con el método deductivo de análisis. En un primer momento, es criticada la opresión patrocinada por el modelo hegemónico de la agricultura, con el fin de fomentar las prácticas de resistencia, especialmente ecofeministas. La falsa exención del derecho agrario en la cuestión de género en el campo, tras una posición a favor del capital. Después, hay contextualización del debate, para que exprese la relación entre el medio rural, el agronegocio, las dificultades de supervivencia que enfrentan las mujeres rurales y el derecho agrario, para relacionar la preocupación con el medio ambiente al feminismo y la necesidad de que el derecho del estado no perpetua la desigualdad de género y construya espacios abiertos de participación efectiva de la mujer rural en tiempos de toma de decisiones. Por último, nociones están indicadas para situar la comprensión de los campesinos y por lo tanto de las mujeres rurales.

Palabras-claves: Derecho agrario, Mujeres rurales, Género, Agronegocios 


\section{INTRODUÇÃO}

As mulheres rurais desempenham inúmeras funções na produção rural brasileira, de acordo com os estudos da Organização das Nações Unidas para Agricultura e Alimentação (FAO) (COTULA, 2007). Nesse sentido, a questão de gênero no campo brasileiro estabelecese como um tema atual e, apesar disso, são poucos os estudos jurídicos que o consagram. Importa que o direito não se esquive da problemática socioeconômica em que as camponesas se inserem, pois o acesso à infra-estrutura necessária para a realização de atividades agrícolas lhes tem sido restringido, como reflexo da desigualdade de gênero que ainda permanece socialmente (COTULA, 2007).

A institucionalização do patriarcado, com discurso cientificista, tende a articular o aparato estatal e seu ordenamento jurídico ao poder econômico e político do agronegócio enquanto modelo agrícola materializador do capitalismo no campo. Devido à realidade de opressões desencadeada por tal articulação, este trabalho representa o início de uma análise crítica ao agronegócio (RAMOS, 2007), inclusive por conta de todos os prejuízos ambientais e humanos que tem provocado.

Pretende-se contextualizar alguns elementos contemporâneos do espaço rural brasileiro, a fim de se situar o estudo que parte de determinada percepção do direito agrário para evidenciar a realidade das camponesas e a importância de suas atividades de produção, especialmente de alimentos. O desenvolvimento deste trabalho visa também estruturar argumentos para exigir a efetiva participação de camponesas em espaços de tomada de decisões políticas e econômicas pertinentes ao campo.

O estudo consagra abordagem comparativa de obras sobre a questão de gênero e direito agrário. Trata-se de análise de dados secundários provenientes do direito agrário em diálogo estreito com a ecologia, também entendida como área do conhecimento. A investigação bibliográfica foi selecionada desde a compreensão da complexidade do tema. Afinal,

Os dados que o pesquisador coleta não vão além dos limites permitidos pelo seu método de investigação e, por isso, resultam de um processo de escolha dirigido pela teoria. Daí a afirmação de que todo dado é construído e, conseqüentemente, toda teoria científica se caracteriza por expressar um conhecimento aproximado, retificável, e não um simples reflexo dos fatos. (MARQUES NETO, 2001, p. 47).

Assim, pretende-se discutir acerca das previsões sobre direito agrário e mulheres rurais. "Em outras palavras, trata-se, através da metodologia, de conhecer o que se faz quando 
se estuda cientificamente algo, quando se adota determinado objeto acerca do qual se entende necessária a especulação.” (BITTAR, 2009, p. 22).

A metodologia, que ampara o desenvolvimento do trabalho, parte de determinada compreensão da realidade vivenciada por uma parcela das mulheres do campo brasileiro. Reconhece-se que a "metodologia tem que ver com a dimensão da busca científica por meio de fontes de estudo para o alcance de resultados científicos; trata-se de um conhecimento sobre os métodos (caminhos) e os meios de praticar ciência.” (BITTAR, 2009, p. 27). Mediante tal entendimento de metodologia, vislumbra-se a necessidade de afunilar, estreitar a gama de ordens interpretativas possíveis, a partir de um referencial teórico pretensamente crítico.

Assim, considerando-se a abrangência do tema e a disposição para se desenvolver um estudo crítico, opta-se pelo método dedutivo, o qual se dispõe "à extração discursiva do conhecimento a partir de premissas gerais aplicáveis a hipóteses concretas." (BITTAR, 2009, p. 18). O raciocínio dedutivo é utilizado neste trabalho, em um primeiro momento, apesar de se admitir que as derivações possíveis das reflexões generalizantes podem não ser suficientes para o entendimento sobre o debate proposto.

O método defendido serve para sustentar a argumentação proposta, o caminho trilhado, um meio escolhido para organizar os pensamentos e a relação da teoria com a necessidade de concretização dos direitos agrários que consagrem o princípio da igualdade de gênero. A estrutura metodológica explicita o modo como se desenvolve o trabalho, a fim de se manter a coerência na construção da pesquisa e a fundamentação de onde e por que se parte de determinadas fontes.

Admite-se a possibilidade de retificação das interpretações sobre o material a ser analisado. Até porque o próprio método de estudo é “construído e retificável [...].” (MARQUES NETO, 2001, p. 74). Assim, a complexidade não pode ser negligenciada com postura simplista pelo direito. Mas há de ser percebida de acordo com Casanova (2006), pois os sistemas de relações sociais complexos são dinâmicos, atentos às diversidades socioculturais, podendo ser adaptativos, como o capitalismo. O olhar jurídico que procura ser crítico para o debate de gênero no campo coloca em questão a estrutura normativa de nosso país, que, por vezes, tende a corroborar com a opressão sofrida pelas mulheres rurais.

Inicialmente, estão relacionadas abordagens sobre o agronegócio, com ênfase nos problemas socioambientais que tem perpetuado. A ótica de estudo consagra o papel das camponesas que frequentemente estão em situação de vulnerabilidade, pressionadas pela 
lógica do modelo agrícola hegemônico (DELGADO, 2012). A partir disso, vale questionar: O que o direito agrário tem a ver com isso? Em tom conclusivo, busca-se localizar o debate sobre campesinato e a mulher rural neste contexto, mediante um referencial que privilegia a interdisciplinaridade. O presente estudo vincula a defesa ecofeminista - cujo sentido está delineado à frente - da importância das atividades das camponesas, para embasar o fato de que o direito agrário precisa aperfeiçoar suas estruturas, a fim de viabilizar propostas para a sobrevivência de camponesas e camponeses. Assim, os reconhecimentos acima justificam a necessidade de estudos jurídicos sobre a complexidade das relações sociais e econômicas vivenciadas pelas camponesas.

\section{POSSIBILIDADES DE DIÁLOGOS ENTRE DIREITO AGRÁRIO E GÊNERO NO CAMPO}

O descompasso entre a importância da atuação da mulher no campo e a persistência de dificuldades históricas vinculadas às suas atividades rurais (NACIONES UNIDAS, 2008) fortalecem a necessidade de se aprofundar estudos sobre o tema.

Mulheres rurais de classe social baixa tendem a estar em condição de maior vulnerabilidade social, econômica e política, se comparadas aos homens de mesma classe. Considera-se vulnerabilidade a sujeição forçada de muitas camponesas à estrutura do modelo agrícola hegemônico, conhecido como agronegócio e seus alicerces, especialmente o aspecto do patriarcado capitalista.

O termo agronegócio é uma tradução da palavra inglesa agribusiness. Assim,

Agribusiness é uma noção puramente descritiva das operações de produção e distribuição de suprimentos agrícolas e processamento industrial, realizada antes, durante e depois da produção agropecuária, cuja soma econômica constituiria uma espécie do novo setor de atividade econômica. Os americanos Davis e Goldberg usaram esta noção em 1957, mas ela já era utilizada independentemente e de longa data por outros autores - de maneira aproximada. As noções de complexos agroindustriais, complexo rural, cadeia produtiva e filière são análogas. (DELGADO, 2012, p. 89).

A predominância da lógica burguesa na organização estatal se reflete na pressão realizada pelo agronegócio para controlar todo o espaço rural brasileiro, por meio de um projeto desenvolvimentista moderno. Na modernidade burguesa, racionaliza-se de modo particular o mundo. "Essa racionalização, enquanto princípio organizativo, define-se como racionalidade instrumental positiva que não liberta, mas reprime, aliena e coisifica o homem." (WOLKMER, 2009, p. 2). 
A alienação e a repressão, inclusive de camponesas, são patrocinadas por uma racionalidade moderna, que no campo impõe o uso de tecnologias de ponta - muitas vezes inacessíveis às mulheres, por conta de histórica discriminação -, da dependência de insumos químicos que enriquecem poucos oligopólios e do sacrifício do meio ambiente, cujas consequências negativas à saúde humana são inegáveis.

O mercado de insumos químicos e, mais especificamente, de agrotóxicos possui influência significativa na política econômica brasileira. Tal fato pode ser reconhecido em dados apresentados no Dossiê ABRASCO (CARNEIRO, 2015, p. 50), pois somente "Em 2010, o mercado nacional movimentou cerca de US\$ 7,3 bilhões e representou 19\% do mercado global de agrotóxicos.” Entre as inúmeras consequências à saúde humana causadas pelo contato com diversos agrotóxicos relacionadas no dossiê citado, ressaltam-se as possibilidades de intoxicações, mutações genéticas e doenças congênitas.

Todavia, a resistência à degradação ambiental - provocada pela lógica produtivista do capitalismo -, inclusive em situações conflituosas, muitas vezes, realiza-se por ações femininas, assim como perceberam Vandana Shiva e Maria Mies (1997). Esta percepção foi uma das motivações para que as autoras produzissem a obra "Ecofeminismo: teoría, crítica y perspectivas" (SHIVA; MIES, 1997).

Um posicionamento ético e, concomitantemente, jurídico há de encarar os conflitos que ainda são cotidianos no campo brasileiro, assim como os dados da Comissão Pastoral da Terra evidenciam (CANUTO; LUZ; COSTA, 2014). Nesse sentido, os conflitos não podem ser tornados invisíveis ou menosprezados, mas devem ser encarados segundo sua complexidade e com observância do princípio da igualdade de gênero. Este princípio prima pela consideração das relações sociais estabelecidas entre mulheres e homens, para que não haja discriminação por motivo de gênero e que sejam consolidadas estruturas sociais e jurídicas específicas de incentivo e suporte diferencial para as mulheres (COTULA, 2007).

No entanto, percebe-se que o princípio da igualdade de gênero não tem sido considerado no âmbito Judiciário, na medida em que se verificam estruturas opressivas institucionalizadas. Este princípio, para ser implementado, depende do respeito à realidade sociocultural heterogênea do campo brasileiro e da não discriminação por gênero. Mas, o Judiciário tende a perpetuar um legalismo discriminatório, cuja interpretação não consagra a necessidade de tratamento por vezes diferencial para atender aos direitos das mulheres. A desconsideração das diferenças de grupos humanos fomenta a opressão social no espaço camponês. 
Um posicionamento coletivo que conteste a estrutura oficial legalista - por vezes violenta, mas imposta como científica - pode se apoiar no pensamento jurídico crítico, construído pela realidade de vítimas da opressão, especialmente a partir da perspectiva latinoamericana com finalidade emancipatória, no sentido considerado por Wolkmer (2009). Neste trabalho, entende-se opressão a partir de Young:

La opresión consiste en procesos institucionales sistemáticos que impiden a alguna gente aprender y usar habilidades satisfactorias y expansivas en medios socialmente reconocidos, o procesos sociales institucionalizados que anulan la capacidad de las personas para interactuar y comunicarse con otras o para expresar sus sentimientos y perspectiva sobre la vida social en contextos donde otras personas puedan escucharlas. (2000, p. 68).

A construção coletiva que há de fazer frente ao legalismo e à cientificidade hegemônicos pode se basear nos conhecimentos interdisciplinares (CASANOVA, 2006) e tradicionais. A contestação às estruturas e ao direito oficiais pode ser reconhecida na ação de algumas camponesas - como as mulheres no Movimento de Mulheres Camponesas (ANMC, 2007) - que se manifestam exigindo das instituições de governo o acesso à terra com dignidade, a disponibilização de serviços de extensão rural, possibilidade de obtenção de créditos rurais e da participação na feitura e no estabelecimento de políticas públicas agrícolas, especialmente quando se pautam por uma releitura de institutos jurídicos e do direito agrário, mediante a experiência popular, consolidando e fazendo movimentar um direito construído, de facetas múltiplas, plurais.

$\mathrm{O}$ direito agrário brasileiro, sob o viés considerado neste trabalho, dedica-se à estruturação jurídica do relacionamento entre os seres humanos e a terra, com ênfase na dinamicidade do contexto rural e a produção de alimentos, como uma das atividades agrárias sobre as quais se debruça (MARQUES, 2015).

O contexto em que as camponesas se inserem exige a atualização do direito agrário em seu estabelecimento doutrinal e positivado -, no sentido de viabilizar a efetivação do princípio da igualdade de gênero no campo. Tal disciplina há de se pautar pelo desenvolvimento de estudos e pesquisas que consagrem abordagens sociais, além das questões econômicas pertinentes à realidade agrícola. O próprio papel, desempenhado por muitas camponesas, de conservação dos recursos ambientais para que a comunidade seja mantida precisa ser pautado no debate do direito agrário. Até porque, ações conservacionistas estão entre os princípios do direito agrário, segundo Marques (2015).

Além disso, a relação entre as pessoas do campo e o meio ambiente, para a produção agrícola, reflete um conjunto de escolhas políticas, muitas vezes sob o peso econômico do 
agronegócio. E o direito agrário, enquanto construção estatal, não se isenta de se posicionar e subsidiar determinado modelo agrícola, predominantemente, o hegemônico. Deste modo, o debate sobre a questão agrária brasileira a partir do direito precisa ser crítico, inclusive mediante o reconhecimento das inúmeras atividades agrárias realizadas pelas camponesas.

A crítica jurídica pode ser percebida inclusive em manifestações de oposição ao modelo agrícola hegemônico, provindas de grupos de camponeses tornados vulneráveis pelo agronegócio e seu controle pretensamente universal dos territórios rurais. Tais manifestações insurgem para legitimar um modo de vida diverso da lógica do capital transnacional, que provém das(os) marginalizadas(os). As insurgências cumprem papel de contra-hegemonia consolidando-se contra a lei imposta ou mesmo que esta não a admita (LYRA FILHO, 1985) -, com potencial de emancipar coletividades na realidade social, rompendo a lógica de dependência do pacote agrícola do agronegócio.

As(os) inconformadas(os) e protagonistas da prática da crítica jurídica gestada no campo podem compartilhar as técnicas subversivas da ordem imposta e legalizada pelo direito oficial, para pensar o direito agrário a partir das mulheres e dos homens do campo.

\section{Contextualização: por que refletir sobre camponesas?}

O modelo agrícola hegemônico no Brasil apresenta estruturas exploratórias que têm o potencial de violar direitos, especialmente direitos agrários de determinadas mulheres rurais. Quanto à compreensão de ruralidade, a partir do texto de José Eli da Veiga (2013), “A dimensão rural do Brasil", reconhece-se a amplitude de entendimentos possíveis acerca da diferença entre os espaços urbano e rural. O autor explica que, no Brasil, prevalece a compreensão de serem urbanas as sedes de municípios ou de distritos. Portanto, os espaços rurais seriam, residualmente, os não inseridos no contexto urbano considerado.

Entretanto, Veiga (2013, p. 282) refere que mais coerente seria considerar a intensidade de alteração humana em determinados lugares para distinguir urbano de rural. Os espaços urbanos se caracterizariam pela maior "pressão antrópica" e, onde esta pressão não for muito intensa haverá espaço rural. Nesse sentido, "são rurais tanto as fontes de baixa entropia quanto a biodiversidade, das quais dependerão as futuras gerações."

Por outro lado, para Milton Santos (2008), por conta do processo de globalização, indivíduos com maior poder político-econômico passam a deter os melhores territórios. Deste modo, de alguns grupos populacionais tem sido retirada a possibilidade de determinar sobre seus próprios modos de vida e destinos. Essa restrição de direitos ocorre de forma evidente no contexto rural brasileiro da atualidade, pois os territórios de agricultura científica moderna se 
tornam, progressivamente, áreas de vulnerabilidades para camponeses e para o meio ambiente. A vulnerabilidade de certas comunidades rurais, especialmente de camponesas, tem-se caracterizado principalmente pelo não acesso à terra e a dificuldade de manutenção no espaço rural.

A própria produção agrícola é determinada pelo mercado. Além disso, a modernização agrícola intensifica a expansão capitalista - já consolidada nas cidades - nos espaços rurais. Todavia, de acordo com o posicionamento de Wood (2000), destaca-se que o capitalismo não surgiu nas cidades, mas se desenvolveu inicialmente no campo, no espaço rural da Inglaterra nos séculos XVI e XVII.

O contexto predominante de desencadeamento das injustiças ambientais é caracterizado pelo agronegócio, enquanto manifestação de capitais relacionados à agropecuária, ao neoliberalismo, aos latifúndios e às empresas transnacionais do ramo, sendo ainda responsável pelo aumento da desigualdade social, conforme Campos (2011).

A perspectiva de Santilli (2009) a respeito de agronegócio estabelece-se de modo ampliado, ressaltando-se a influência de padrões internacionais para a formação dos produtos, a submissão dos produtores rurais ao pacote agrícola ofertado no mercado, abrangendo insumos químicos e maquinário. Além disso, no agronegócio também se destacam as características de monoculturas, formação em latifúndios e artificialização dos territórios.

Contudo, nesse espaço rural há de se identificar a questão de gênero, em especial os direitos relativos à mulher rural. Em termos interpretativos, o princípio da igualdade de gênero pode servir como referência na análise de publicações de cunho jurídico pertinentes à questão de gênero no campo, a exemplo da obra publicada pela FAO (COTULA, 2007), "Género y legislación: los derechos de la mujer en la agricultura”. Nesta publicação, observase que o termo "sexo" se vincula à fatores biológicos e de cunho universal. Diferentemente da palavra "gênero", que se embasa em elementos culturais, sociais e históricos das relações entre as pessoas.

Muitas mulheres rurais são atingidas por atitudes de discriminação sócio-cultural. Nesse bojo, reconhece-se a complexidade pertinente aos cenários de tensão social vivenciados por camponesas face à estrutura de poder dos empresários do agronegócio e o aparato institucional agrícola que tende a negar direitos agrários para essas mulheres rurais.

As mulheres desempenham importante papel produtivo na economia mundial. "Sin embargo, frecuentemente se enfrentan con trabas a la hora de acceder a la tierra y a otros recursos naturales, a un empleo regulado, y a los servicios de crédito, formación y extensión agrícola." (COTULA, 2007, p. iii). Entre as principais dificuldades podem-se destacar as 
relativas à discriminação social contra a mulher e a estrutura do aparato normativo, inadequado às questões de gênero, quando não causadora de empecilhos ao trabalho feminino no campo.

As recentes e tecnológicas mudanças pelas quais a agricultura tem passado oferecem maiores dificuldades de sobrevivência no campo para mulheres de classe social baixa, que sofrem a pressão expansionista do modelo agrícola hegemônico.

Los actuales procesos de globalización, como la comercialización de la agricultura, la liberalización del comercio internacional y de los mercados de productos alimenticios y de otros productos agrícolas, la acentuación de la migración de la mano de obra y la privatización de recursos y servicios afectan al desarrollo rural. (NACIONES UNIDAS, 2008, p. 2).

O espaço rural vê-se envolvido e amarrado à lógica capitalista de mercado. As camponesas e os camponeses desprivilegiados são, porém, inseridos nesse processo que lhes tem retirado historicamente a soberania alimentar. A Organização das Nações Unidas, por meio de seu Departamento de Assuntos Econômicos e Sociais, tem admitido o vínculo necessário entre a mulher rural e a segurança alimentar, principalmente no campo. Este posicionamento se insere no estabelecimento de possibilidades de processos intergovernamentais (NACIONES UNIDAS, 2008).

Predominantemente, as mulheres desempenham muitas atribuições econômicas e sócio-afetivas nas comunidades rurais. Por conta disso, debates mundiais envolvendo crise no abastecimento de alimentos e mudanças climáticas dependem do conhecimento e da experiência feminina, em sua pluralidade de vivências e costumes.

A própria Constituição Federal, vigente em nosso país, pauta-se pela proteção aos direitos das mulheres. Porém, a prática das relações humanas camponesas pode se distanciar das previsões constitucionais e legais.

A atuação feminina no campo tende a se relacionar com a manutenção do abastecimento da família e, por vezes, as responsabilidades são aumentadas quando a mulher passa a ser quem produz a renda. "En este contexto, muchas mujeres rurales están trabajando intensamente para garantizar y mejorar su acceso a los recursos y actividades de subsistencia." (COTULA, 2007, p. 2).

O trabalho de mulheres rurais é significativo em contexto mundial, em especial no que diz respeito à produção de alimentos para o consumo humano. Desta maneira,

Según datos de la Organización Internacional del Trabajo (OIT), en 2006 el $40,4 \%$ del total de mujeres empleadas trabajaba en la agricultura. La mitad de la producción mundial de alimentos se debe a las trabajadoras agrícolas y 
éstas son las principales productoras de cultivos básicos, que representan entre el $60 \%$ y el $80 \%$ del consumo de alimentos en los países en desarrollo. (NACIONES UNIDAS, 2007, p. 3).

No contexto de sobrevivência e protagonismo socioeconômico das mulheres no campo, importa relacionar criticamente os (des)usos do direito agrário brasileiro no que tange à igualdade de gênero. Percebe-se a importância econômica relacionada à agricultura empresarial em nosso país - especialmente a partir do período de governo militar, pela "modernização conservadora" e da imposição neoliberal do agronegócio, com destaque a partir dos anos 2000 (DELGADO, 2012, p. 77). Este modelo patronal de agricultura é dependente dos setores de indústrias transnacionais em contraste com a produção em pequena escala e de gêneros alimentícios de camponesas e camponeses. Contudo, as crises econômicas que afetam a agricultura, em sentido amplo, podem ser sentidas com maior intensidade pelas mulheres camponesas que não dispõem de capital próprio para investirem na produção.

Em diversa perspectiva, a relação estreita entre mulher rural e preservação do espaço agrário/socioambiental dialoga especialmente com a atuação teórica e prática de ecofeministas.

Una perspectiva ecofeminista propugna la necesidad de una nueva cosmología y una nueva antropología que reconozcan que la vida en la naturaleza (que incluye a los seres humanos) se mantiene por medio de la cooperación, el cuidado mutuo y el amor. Sólo así podremos llegar a ser capaces de respetar y preservar la diversidad de todas las formas de la vida, incluidas sus expresiones culturales, como verdaderas fuentes de nuestro bienestar y nuestra felicidad. Con esta finalidad, las ecofeministas utilizamos metáforas como "retejer el mundo", "sanar las heridas" y reconectar e interconectar la "red". Este esfuerzo para crear una cosmología y una antropología holísticas que engloben toda la vida debe incluir forzosamente un concepto de libertad distinto del que ha venido empleándose desde la Ilustración. (SHIVA; MIES, 1997, p. 15).

Alguns costumes excludentes da participação feminina em cenários políticos; dificuldades socioeconômicas de acesso ao Judiciário; desconhecimento das leis e a carência de legitimidade socialmente atribuída às instituições estatais podem estar entre os elementos que restringem direitos das mulheres rurais.

Mas, em uma análise ampliada, observa-se que, no contexto rural/agrário, muitos sujeitos resistem mesmo cercados pelo agronegócio (RAMOS, 2007), tentando manter suas construções de saberes e modos de vida próprios, contestando as estruturas de poder oficiais, exigindo o direito de acesso à terra com dignidade. A contestação manifesta-se, muitas vezes, para sustentar um modelo agrícola e um modo de vida campesino, diverso do hegemônico. 
Esta forma de lidar com a terra, valorizando os conhecimentos tradicionais, estabelecese na conjuntura histórica do povo camponês - no sentido apresentado ao fim deste tópico, de acordo com Wanderley (1996) - que trabalha na terra e abastece as mesas dos brasileiros, não transformando sua produção em commodities, como fazem os agricultores que expandem o agronegócio. Estes, predominantemente, integram a classe burguesa e necessitam

do desenvolvimento científico para produzirem insumos químicos, entre fertilizantes, agrotóxicos e outras substâncias, além de máquinas e equipamentos tecnológicos, que padronizam e tornam artificiais as plantações, inclusive com uso de organismos geneticamente modificados. Todos esses elementos e outros configuram o pacote tecnológico do agronegócio (SANTILLI, 2009).

O paradigma da cientificidade subsidia o agronegócio. Afinal, “a ciência não é neutra e depende das escolhas de cada um colocá-la a serviço da humanidade, de sua liberdade, ou a serviço do capital." (MOLINA; SOUSA JÚNIOR; TOURINHO NETO, 2002, p. 32). A ciência ocidental, por vezes, revela seu caráter totalitário tanto em questões de tecnologias agrícolas quanto em imposições de um direito estatal, dito científico, especialmente ao desconsiderar e subjugar modos de racionalidade diversos da ocidental e moderna.

A obra “A crítica da razão indolente", de Boaventura de Sousa Santos (2011) contribui teoricamente para se questionar se a ciência moderna traz felicidade para a vida das pessoas. $\mathrm{O}$ paradigma da cientificidade tende a menosprezar conhecimentos distintos de suas bases, não admitindo a validade de conhecimentos tradicionais de comunidades campesinas.

O autor escancara a falácia do discurso científico-desenvolvimentista (SANTOS, 2011). Afinal, mesmo que as experiências de organização social passadas tenham sido frágeis, parece certo que as expectativas quanto ao futuro são piores. Existem riscos socioambientais crescentes, os quais afugentam possíveis perspectivas esperançosas.

São inúmeros os aspectos do capitalismo prejudiciais à vida. Desta maneira, importa escancarar a pressão e a violência sofridas por camponesas e camponeses em espaços de conflitos com latifundiários, coronéis, pessoas responsáveis pela grilagem de terras e empresas transnacionais que exploram o capital agrário.

O agronegócio com seus métodos exploratórios e expansionistas e o Estado nacional que lhe apoia - inclusive negando formas jurídicas distintas da normatividade oficial - dão causa ao desencadeamento de conflitos no campo. O direito oficial não protege as comunidades camponesas. Esta ausência de proteção por parte do direito embasa o fato de, a partir do pósguerra, ter havido incremento do número de litígios que são judicializados. Paralelamente, percebe-se que conflitos no campo persistem (CANUTO; LUZ; COSTA, 
2014). "Esse contexto social de resistência é uma das razões para o surgimento da crise de administração da justiça ao lado da crise de identidade e de referências políticas." (GUSTIN; DIAS, 2010, p. 20). A partir desta reflexão, faz-se justificável situar o uso do termo campesinato, por meio da relação com o direito agrário e o debate sobre a questão de gênero no campo.

O sentido empregado por Wanderley (1996), para a noção de campesinato, considera que a agricultura familiar contemporânea como um gênero, a partir do qual o campesinato se apresenta como espécie. Deste modo, ao se estudar sobre a relação entre o direito agrário e a atuação política, econômica e social das camponesas, trata-se das integrantes de comunidades rurais de classe social baixa, atreladas a uma pluralidade de influências históricas, sociais e culturais em nosso país.

Mas, a reflexão sobre campesinato pode partir da conjuntura socioeconômica determinante das tomadas de decisões e as influências familiares, assim como Abramovay (1998) reconhece ser pertinente. Este autor destaca a importância de que a questão camponesa abarque estudos sobre os contextos de escolhas sociais e econômicas e a racionalidade específica de camponeses, historicamente considerados.

O campesinato possui certa autonomia em termos econômicos, sociais e demográficos, especialmente por conta de suas tradições produtivas - entre elas o sistema policultura-pecuária - e da sua base familiar, de acordo com Wanderley (1996). Os camponeses predominantemente realizam atividades diversificadas e independentes em seus espaços. Nessa análise, Abramovay (1998) explica que a realidade camponesa de trabalho e produção não se insere totalmente na lógica de mercado e os elementos mercantis presentes no campesinato são incompletos. Predominantemente, os camponeses não se subordinam de modo rígido às imposições do mercado.

Entretanto, em determinadas situações há estabelecimento de rotina árdua de funções a serem desempenhadas, pela necessidade de manutenção dos camponeses e como reflexo do acúmulo dos conhecimentos tradicionais. Há situações em que os camponeses além de trabalharem internamente, para a sobrevivência da família, também precisam desempenhar um trabalho exterior (ABRAMOVAY, 1998). Este trabalho é denominado por Kautsky (1980) de trabalhos acessórios, realizados por camponeses quando as necessidades financeiras exigem, pois a pequena produção, que ocorre por épocas de plantios, por vezes não traz lucros suficientes para a manutenção da família.

Destaca-se que o modo de vida camponês consagra perspectiva geracional, de cuidado com os integrantes da comunidade e preservação ambiental (WANDERLEY, 1996). 
A sociabilidade camponesa tende a agregar aspectos afetivos, de convívio familiar e comunitário, normatividade consuetudinária, compartilhamento de valores e primazia de certo estilo de vida em detrimento das determinações economicistas do capital.

O relacionamento social camponês revela, muitas vezes, influências patronais, clientelistas e de subordinação classista para com comerciantes ou latifundiários, distantes da concorrência capitalista. Certas dificuldades se apresentam com frequência para comunidades camponesas, como a restrição de acesso às informações e à infra-estrutura pertinentes as atividades rurais, inclusive aos créditos (ABRAMOVAY, 1998). Porém, tais dificuldades são intensificadas quando se trata de mulher camponesa, fato que justifica a reflexão que a envolve a partir do direito agrário.

$\mathrm{Na}$ contemporaneidade, a agricultura familiar tende a refletir os aspectos sociais e econômicos predominantes na sociedade. No entanto, determinados modos de vida e tradições permanecem e se adaptam ao contexto social. A realidade não é padronizada, pois há camponeses que não conseguem o mínimo acesso à estrutura de produção agrícola vivenciando uma pobreza intensa no campo - e outros que se inserem no mercado, profissionalizando a agricultura, no sentido capitalista.

Assim, "O ambiente no qual se desenvolve a agricultura familiar contemporânea é exatamente aquele que vai asfixiar o camponês, obrigá-lo a se despojar de suas características constitutivas, minar as bases objetivas e simbólicas de sua reprodução social." (ABRAMOVAY, 1998, p. 131). Portanto, percebe-se que, para Abramovay (1998), o campesinato se distingue e tende a ser suprimido pela agricultura familiar. Mediante todo esse contexto, os modos camponeses de enfrentamento à opressão promovida pelo modelo socioeconômico hegemônico são plurais e refletem a experiência popular, em meio às violências sofridas.

\section{CONSIDERAÇÕES FINAIS}

O desenvolvimento deste trabalho demonstra a necessidade de se pautar pelo debate interdisciplinar para a articulação entre as questões de gênero e agrária em nosso país. A problemática vivenciada conjunturalmente pelas camponesas se estabelece frente ao direito agrário estatal exigindo sua renovação e democratização.

O agronegócio realiza pressão socioeconômica e política para expandir seu modelo de agricultura tecnificada, envenenada (e envenante), deixando muitos camponeses acuados e com dificuldades para prosseguirem um modo contra-hegemônico de produção e de vida. O 
modo de vida camponês e as atividades agrárias realizadas pelas camponesas tende a contestar o agronegócio e a cientificidade moderna.

Especificou-se, na pesquisa, certa noção de ruralidade e como ela é encarada pelo direito agrário, segundo o referencial selecionado como pertinente sobre essa disciplina jurídica. A partir dessa análise foi possível afirmar com segurança o papel fundamental das mulheres rurais para a soberania alimentar nacional.

Assim, na medida em que se percebe que a acesso desigual por motivo de gênero aos recursos para a produção agrícola, à titulação da terra e sua manutenção nela ainda persiste, por vezes de modo velado, faz-se coerente a cobrança para que os atores da luta para que o direito se vista de justiça, inclusive no campo, sejam integrantes de grupos humanos plurais. Em concordância com a especificidade seguida por este estudo, importa que às camponesas seja viabilizado o acesso aos cenários de elaboração de políticas públicas e normas relacionadas ao campo. Até porque, conforme percebido acima, mulheres rurais - especialmente as vinculadas ao campesinato - são atoras de destaque na realização de atividades agrícolas, a despeito de seus trabalhos tenderem a ser menosprezados socialmente.

As camponesas necessitam de tratamento sócio-jurídico pautado no princípio da igualdade de gênero. Contudo, reconhece-se que previsões legais são insuficientes para provocar mudanças sociais no sentido resultar em respeito e valorização das mulheres rurais. Mas a estruturação do direito agrário, em sentido amplo, precisa se posicionar de modo crítico às opressões sofridas por camponesas, viabilizando recursos jurídicos para reduzir tais práticas que refletem a força do patriarcado rural e capitalista.

A relação dos seres humanos com a terra, que o direito agrário estatal pretende balizar, apenas pode ser debatida com o suporte das noções de ecologia e, com a especificidade neste trabalho defendida, noções ecofeministas que são mais sensíveis ao vínculo entre a vulnerabilidade do meio ambiente e das mulheres devido à lógica expansionista e degradante do capitalismo.

Camponesas que não amoldam seus modos de produzir na terra às imposições do modelo agrícola hegemônico, sofrem a negação de direitos, em especial de direitos agrários. Por conta disso, o direito agrário está ligado profundamente ao contexto de opressão enfrentado pelas camponesas, inclusive contribuindo para que se perpetue, ao aparentar isenção ou ao oferecer subsídios legais para a expansão do agronegócio.

Portanto, direito agrário não pode ser dissociado da realidade das camponesas, com os conflitos que elas vivenciam, com o estrangulamento do modo de vida e produção camponês e com a discriminação por motivo de gênero que permanece principalmente no que 
tange à produção resultante das atividades agrárias de camponesas. O direito agrário que, em teoria, valoriza a dinamicidade das relações presentes no campo, não tem conseguido apontar possibilidades para a superação de atrasos relacionados ao tratamento desigual que as camponesas são vítimas. Esta disciplina jurídica revela, na prática, seu perfil não dinâmico e atrofiado, quando não apresenta propostas de espaços de participação das camponesas em situações de tomada de decisões pertinentes à realidade agrícola.

\section{REFERÊNCIAS}

ABRAMOVAY, Ricardo. Paradigmas do capitalismo agrário em questão. 2. ed. São Paulo-Campinas: Hucitec e Editora da UNICAMP, 1998.

ALIER, Joan Martínez. O ecologismo dos pobres: conflitos ambientais e linguagem de valoração. Tradução de Maurício Waldman. São Paulo: Contexto, 2007.

ANMC - Associação Nacional de Mulheres Camponesas. Movimento de Mulheres Camponesas: organizar a base, produzir alimentos saudáveis, construir caminhos de libertação. Passo Fundo-RS: Secretaria Nacional da ANMC, 2007. Disponível em: <http://www.mmcbrasil.com.br/site/materiais/download/cartilha_tbase2007.pdf>. Acesso em: 07 jun. 2015.

BITTAR, Eduardo C. B. Metodologia da pesquisa jurídica: teoria e prática da monografia para os cursos de direito. 7. ed. São Paulo: Saraiva, 2009.

BOGO, Ademar. Identidade e luta de classes. 2. ed. São Paulo: Expressão Popular, 2010.

BOMBARDI, Larissa Mies. Agrotóxicos e agronegócio: arcaico e moderno se fundem no campo brasileiro. In: MERLINO, Tatiana e MENDONÇA, Maria Luisa (orgs.). Direitos Humanos no Brasil 2012: Relatório da Rede Social de Justiça e Direitos Humanos. São Paulo, 2012. p. 75-85.

BRUMER, Anita; PIÑERO, Diego. Agricultura Latino-americana: novos arranjos e velhas questões. Porto Alegre: Editora da UFRGS, 2005.

CAMPOS, Christiane Senhorinha Soares. A face feminina da pobreza em meio à riqueza do agronegócio: trabalho e pobreza das mulheres em territórios do agronegócio no Brasil: o caso de Cruz Alta/RS. Buenos Aires: CLACSO, 2011. 208 pp.

CANUTO, Antônio; LUZ, Cássia Regina da Silva; COSTA, Edmundo Rodrigues (coord.). Conflitos no campo - Brasil 2014. Goiânia: CPT Nacional, 2014.

CARNEIRO, Fernando Ferreira et. al. (Org.). Dossiê ABRASCO: um alerta sobre os impactos dos agrotóxicos na saúde. Rio de Janeiro: EPSJV; São Paulo: Expressão Popular, 2015. 
CARSON, Rachel. Primavera silenciosa. Tradução de Raul de Polillo. 2. ed. São Paulo: Melhoramentos, 1969.

CASANOVA, Pablo González. As novas ciências e as humanidades: da academia à política. São Paulo: Boitempo Editorial, 2006. pp. 65-118.

COELHO, Edemilson Moreira; LEE, Francis. Agricultura e meio ambiente: um contrassenso? Revista UFG - Dossiê agronegócio e meio ambiente. Goiânia: Universidade Federal de Goiás, 2009. ISSN 1677-9037.

COLBORN, Theo; DUMANOSKI, Dianne; MYERS, John Peterson. O futuro roubado. Porto Alegre: L\&PM, 2002.

COSTA, A. B. (org.) et al. O Direito Achado na Rua - Introdução Crítica ao Direito à Saúde. Brasília: CEAD/UnB, 2009.

COTULA, Lorenzo. Género y legislación: los derechos de la mujer en la agricultura. Organización de las Naciones Unidas para la Agricultura y la Alimentación (FAO). Roma, 2007. ISBN 978-92-5-305563-0. Disponível em: 〈http://www.fao.org/3/a-y4311s.pdf〉. Acesso em: 20 mar. 2015.

DELGADO, Guilherme Costa. Do "capital financeiro na agricultura" à economia do agronegócio: mudanças cíclicas em meio século (1965-2012). Porto Alegre: Editora da UFRGS, 2012.

DUSSEL, Enrique. 1492: o encobrimento do outro: a origem do mito da modernidade: Conferências de Frankfurt. Tradução de Jaime A. Clasen. Petrópolis: Vozes, 1993.

FREIRE, Paulo. Pedagogia do oprimido. 17. ed. Rio de Janeiro: Paz e Terra, 1987.

GUSTIN, Miracy Barbosa de Sousa; DIAS, Maria Tereza Fonseca. (Re)pensando a pesquisa jurídica: teoria e prática. 3. ed. rev. e atual. Belo Horizonte: Del Rey, 2010.

HARVEY, David. A produção capitalista do espaço. Tradução de Carlos Szlak. São Paulo: Annablume, 2005.

KAUTSKY, Karl. A questão agrária. Tradução de C. Iperoig. 3. ed. São Paulo: Proposta Editorial, 1980.

LACERDA, Rosane Freire. "Volveré, y Seré Millones": Contribuições Descoloniais dos Movimentos Indígenas Latino Americanos para a Superação do Mito do Estado-Nação. Tese (Doutorado). Brasília - DF: Universidade de Brasília - UnB. Faculdade de Direito, 2014. 2 vols.

LARANJEIRA, Raymundo. Propedêutica do direito agrário. São Paulo: LTr, 1975.

LONDRES, Flavia. Agrotóxicos no Brasil: um guia para ação em defesa da vida. Rio de Janeiro: AS-PTA - Assessoria e Serviços a Projetos em Agricultura Alternativa, 2011. 190 pp. 
LYRA FILHO, Roberto. O que é Direito. 5. ed. São Paulo: Brasiliense, 1985.

MARQUES, Benedito Ferreira. Direito agrário brasileiro. 11. ed. rev. e ampl. São Paulo: Atlas, 2015.

MOLINA, Mônica Castagna; SOUSA JÚNIOR, José Geraldo de; TOURINHO NETO, Fernando da Costa (orgs.). Introdução crítica ao direito agrário. Brasília, Universidade de Brasília, Decanato de Extensão, Grupo de Trabalho de apoio à Reforma Agrária, São Paulo: Imprensa Oficial do Estado, 2002.

NACIONES UNIDAS. La mujer rural en un mundo cambiante: oportunidades y retos. La mujer en el 2000 y después. Octubre 2008. Disponível em:

<http://www.un.org/womenwatch/daw/public/w2000/Rural\%20Women\%20\%28Spanish\%29. pdf>. Acesso em: 20 mar. 2015.

NACIONES UNIDAS. Mejoramiento de la situación de la mujer en las zonas rurales. Informe del Secretario General. A/62/202. Distr. General. 3 ago. 2007. Disponível em: $<$ http://www.iidh.ed.cr/comunidades/derechosmujer/docs/dm_onuseguimiento/agres56129.pd f>. Acesso em: 23 mar. 2015.

QUIJANO, Aníbal. Colonialidad del poder, eurocentrismo y América Latina. In: Edgardo Lander (org.). La colonialidad del saber: eurocentrismo y ciencias sociales. Perspectivas Latinoamericanas. Buenos Aires: Consejo Latinoamericano de Ciencias Sociales (CLACSO), 2000 .

RABENHORST, Eduardo Ramalho. O feminismo como crítica do direito. Revista eletrônica Direito e Política. Programa de Pós-Graduação Stricto Sensu em Ciência Jurídica da UNIVALI, Itajaí, v. 4, n. 3, 2009. Disponível em:

<http://www6.univali.br/seer/index.php/rdp/article/view/6141>. Acesso em: 24 mar. 2015.

RAMOS, Pedro (org.). Dimensões do agronegócio brasileiro: políticas, instituições e perspectivas. Brasília: MDA, 2007.

SANTILLI, Juliana. Agrobiodiversidade e direitos dos agricultores. São Paulo: Peirópolis, 2009.

SANTOS, Boaventura de Sousa. A crítica da razão indolente: contra o desperdício da experiência. 8. ed. v. 1. São Paulo: Cortez, 2011.

SANTOS, Boaventura de Sousa. Para além do Pensamento Abissal: Das linhas globais a uma ecologia de saberes. Revista Crítica de Ciências Sociais, 78, Outubro 2007: 3-46.

Disponível em:

$<$ http://www.ces.uc.pt/myces/UserFiles/livros/147_Para\%20alem\%20do\%20pensamento\%20 abissal_RCCS78.pdf>. Acesso em: 02 set. 2014.

SANTOS, Milton. Por uma outra globalização: do pensamento único à consciência universal. 16. ed. Rio de Janeiro: Record, 2008.

SERRES, Michel. O contrato natural. Tradução de Serafim Ferreira. Lisboa: Instituto Piaget, 1990. 
SHIVA, Vandana. Monoculturas da mente: perspectivas da biodiversidade e da biotecnologia. Tradução de Dinah de Abreu Azevedo. São Paulo: Gaia, 2003.

SHIVA, Vandana; MIES, Maria. Ecofeminismo: teoría, crítica y perspectivas. Tradução de Mireia Bofill, Eduardo Iriarte e Marta Péres Sánchez. Barcelona: Icaria e Antrazyt, 1997. pp. 239.

SOUZA FILHO, Carlos Frederico Marés. O renascer dos povos para o Direito. Curitiba: Juruá, 1998.

STEDILE, João Pedro (org.). A questão agrária no Brasil: O debate na esquerda - 19601980. São Paulo: Expressão Popular, 2005. 320 pp.

TÁRREGA, Maria Cristina Vidotte Blanco; MAIA, Cláudio Lopes; FERREIRA, Adegmar José. Observatório da atuação do Poder Judiciário nos conflitos agrários decorrentes de ocupações de terra por movimentos sociais nos estados do Pará, Mato Grosso, Goiás e Paraná (2003-2011): Relatório Final de Pesquisa. Goiânia: Universidade Federal de Goiás / Faculdade de Direito, 2012.

VEIGA, José Eli da. A dimensão rural do Brasil. In: STEDILE, João Pedro (org.). A questão agrária do Brasil: o debate na década de 2000. São Paulo: Expressão Popular, 2013.

WANDERLEY, Maria de Nazareth Baudel. Raízes históricas do campesinato brasileiro. XX encontro anual da ANPOCS. GT 17. Processos sociais agrários. Caxambu - MG. Outubro 1996.

WOLKMER, Antonio Carlos. Introdução ao pensamento jurídico crítico. 7. ed. São Paulo: Saraiva, 2009.

WOOD, Ellen Meiksins. As origens agrárias do capitalismo. In: Revista Crítica Marxista, n. 10, ano 2000. São Paulo: Boitempo. p. 12-30.

YOUNG, Iris Marion. La justicia y la política de la diferencia. Tradução de Silvina Álvarez. Universitat de València, 2000. 